\title{
Erratum to: Effects of Premature Termination Codon Polymorphisms in the Drosophila pseudoobscura Subclade
}

Kenneth B. Hoehn · Suzanne E. McGaugh • Mohamed A. F. Noor

Published online: 22 December 2012

(c) Springer Science+Business Media New York 2012

Erratum to: J Mol Evol (2012) 75:141-150

DOI 10.1007/s00239-012-9528-x

Our original paper neglected to acknowledge that Steve Schaeffer and Andre Wallace genotyped and provided the Pikes Peak lines of Drosophila pseudoobscura for sequencing. We thank them for this contribution and apologies for neglecting to mention it directly.

The online version of the original article can be found under doi:10.1007/s00239-012-9528-x. 